\title{
Fuel pellets from biomass: The importance of the pelletizing pressure and its
} dependency on the processing conditions

Stelte, Wolfgang; Holm, Jens K.; Sanadi, Anand R.; Barsberg, Søren; Ahrenfeldt, Jesper; Henriksen, Ulrik Birk

\section{Published in:}

Fuel

Link to article, DOI:

10.1016/j.fuel.2011.05.011

Publication date:

2011

Link back to DTU Orbit

Citation (APA):

Stelte, W., Holm, J. K., Sanadi, A. R., Barsberg, S., Ahrenfeldt, J., \& Henriksen, U. B. (2011). Fuel pellets from biomass: The importance of the pelletizing pressure and its dependency on the processing conditions. Fuel, 90(11), 3285-3290. https://doi.org/10.1016/j.fuel.2011.05.011

\section{General rights}

Copyright and moral rights for the publications made accessible in the public portal are retained by the authors and/or other copyright owners and it is a condition of accessing publications that users recognise and abide by the legal requirements associated with these rights.

- Users may download and print one copy of any publication from the public portal for the purpose of private study or research.

- You may not further distribute the material or use it for any profit-making activity or commercial gain

- You may freely distribute the URL identifying the publication in the public portal 


\title{
Fuel pellets from biomass: The importance of the pelletizing pressure and its dependency on the processing conditions
}

\author{
Wolfgang Stelte ${ }^{a^{*}}$, Jens K. Holm ${ }^{b}$, Anand R. Sanadi ${ }^{c}$, Søren Barsberg ${ }^{c}$, Jesper Ahrenfeldt $^{a}$ and Ulrik \\ B. Henriksen ${ }^{a}$ \\ *Corresponding author: Phone: +45 4677 4183, Fax: +4546774109,E-mail: wost@risoe.dtu.de \\ ${ }^{a}$ Biosystems Division, Risø National Laboratory for Sustainable Energy, Technical University of Denmark-DTU, \\ Frederiksborgvej 399, DK 4000, Roskilde, Denmark, \\ ${ }^{b}$ Chemical Engineering, DONG Energy Power A/S, A.C. Meyers Vange 9, DK 2450, Copenhagen SV, Denmark. \\ ${ }^{c}$ Forest \& Landscape Denmark, Faculty of Life Sciences, University of Copenhagen, Rolighedsvej 23, DK-1985 \\ Frederiksberg C, Denmark.
}

The aim of the present study was to identify the key factors affecting the pelletizing pressure in biomass pelletization processes. The impact of raw material type, pellet length, temperature, moisture content and particle size on the pressure build up in the press channel of a pellet mill was studied using a single pellet press unit. It was shown that the pelletizing pressure increased exponentially with the pellet length. The rate of increase was dependent on biomass species, temperature, moisture content and particle size. A mathematical model, predicting the pelletizing pressure, was in good accordance with experimental data. It was shown that increasing the temperature resulted in a decrease of the pelletizing pressure. Infrared spectra taken from the pellets surface, indicated hydrophobic extractives on the pellet surface, for pellets produced at higher temperatures. The extractives act as lubricants, lowering the friction between the biomass and the press channel walls. The effect of moisture content on the pelletizing pressure was dependent on the raw material species. Different particle size fractions, from below $0.5 \mathrm{~mm}$ up to $2.8 \mathrm{~mm}$ diameter, were tested, and it was shown that the pelletizing pressure increased with decreasing particle size. The impact of pelletizing pressure on pellet density was determined, and it was shown that a pelletizing pressure above 200 MPa resulted only in minor increase in pellet density. 
Keywords: Biomass, Biofuels, Pellets, Wood, Straw, Pelletizing pressure, processing conditions

\section{Introduction}

The utilization of biomass for heat and power production is becoming increasingly important, due to the desire to reduce carbon dioxide emissions into the atmosphere. Plant biomass is available in large quantities, and can be utilized for sustainable heat and power production, when used as fuel $[1,2]$. However, often long distances have to be bridged between the biomass place of origin and the place of its utilization, resulting in expensive handling and transportation. Wood and plant materials have in general low densities due to their porous structure with densities ranging from $40-150 \mathrm{~kg} / \mathrm{m}^{3}$ for grass type biomass [3,4] and 320-720 kg/m 3 for most types of dried hard- and softwoods [5]. The bulk density of commercial wood chips ranges between $150-200 \mathrm{~kg} / \mathrm{m}^{3}$ [6], and is in general less than the solid wood they are produced from. To increase the density of the biomass, it can be compressed into pellets using a mechanical process in which pressure is applied to the biomass to crush its cellular structure, and thereby increasing its density. Typical unit densities of biomass pellets can be as high as 1000 to $1400 \mathrm{~kg} / \mathrm{m}^{3}$ [7], and bulk densities are about $700 \mathrm{~kg} / \mathrm{m}^{3}$ [8]. Major benefits of pelletizing biomass are: A higher energy density, lower transportation and storage costs, combined with standardized sizes and composition, which allows automatic feeding in domestic and industrial sized boilers. The growing domestic and industrial demand of biomass for heat and power production in many countries has resulted in a strong growing global pellet marked during the last decades, and continuous growth of the market is predicted for the next years [9]. The main raw materials used are wood residues, such as saw dust, wood shavings and wood chips, but also agro-residues, such as straw, waste products of the food industry and fuel crops, are used for the production of fuel pellets $[10,11]$.

Most pellets today are produced in pellet mills of the ring die type [12]. The acting forces in a press channel of a ring die type pellet mill have been reviewed in detail in two earlier studies [13,14], and it was shown that under steady state conditions the pelletizing pressure $\left(P_{x}\right)$ can mathematically be expressed as:

$$
P_{x}=\frac{P_{N 0}}{v_{L R}}\left(e^{4 \mu v_{L R} c}-1\right)
$$

(Equation 1) 
With $c$ being the compression ratio:

$$
c=\frac{x}{2 r}
$$

(Equation 2)

$P_{\mathrm{N} 0}$ is a pre-stressing pressure incorporating plasticity in the model, $v_{\mathrm{LR}}$ is the Poisson's ratio. The first index $L$ denoted the direction of applied stress ( $L=$ longitudinal fiber axes), and the second one $\mathrm{R}$ the direction of transverse deformation ( $R=$ radial fiber axes). $\mu$ is the friction coefficient and $c$ is the compression ratio, defined as the ratio between the length of the pellet in the die $(x)$ and diameter (2r) (Equation 2).

Equation 1 shows that $P_{\mathrm{x}}$ increases exponentially with the pellet length, while keeping the other parameters constant. The model has recently been used to predict $P_{\mathrm{x}}$ for pelletizing beech and pine, by carrying out a least square fit of the model given in Equation 1 to the press data [13]. However the model does so far not directly include important processing parameters such as temperature, material moisture content or particle size.

It is likely, that a change in any of those processing parameters will have an effect on $P_{\mathrm{x}}$, and thereby on the necessary pressure exerted by the roller. Within a certain range, this pressure is adjustable to the same magnitude as $P_{\mathrm{x}}$. In case $P_{\mathrm{x}}$ exceeds this range and becomes too high, the pellet mill will be plugged, as the rollers are not able to provide the necessary pressure to push the material out. High $P_{\mathrm{x}}$ not only increases the risk of fires, due to high friction, which causes a high temperature increase, but also results in unnecessarily high energy uptake of the pellet mill. In the case, $P_{\mathrm{x}}$ is too low; pellets of acceptable quality cannot be produced.

Nielsen et al. [15-18] have investigated several different aspects influencing the energy consumption of the pelletizing process and the mechanical properties of the produced pellets. The pelletizing parameters studied were temperature, moisture content [17], fiber orientation [15], raw material extractive content [18] and their change during storage time [16]. The studies were primarily based on short pellets of a few millimeters in length. If short pellets are tested, the exponential pellet length dependency is suppressed, and any temperature or moisture effects might be overestimated, in relation to the behavior in a large scale pellet mill, with significantly longer press channels.

The challenge in biomass pelletization is therefore to keep the pressure in the range where high quality pellets are produced, at a minimal energy input and at a high pellet mill capacity. Hence, it is critical to know, how and which of the controllable process parameters affect $P_{x}$. The effect of temperature, moisture content and particle size at higher ' $c$ ' is necessary. This will give information and data closer to commercial pelletizing applications, while using a single pellet press unit will help 
selecting proper pelletizing conditions in real situations. It should be noted that the published model allows predictions of $P_{\mathrm{x}}$ at greater $c$ based on experimental data.

The objective of the present study was to identify the key process parameters affecting $P_{x}$ by conducting test using a single pellet press unit (SPP-unit). Process parameters included in this study were species, pellet length, die temperature, moisture content, particle size, and $c$.

\section{Experimental}

\subsection{Materials}

Three different raw materials were used for the present study, representing three different raw material classes used for fuel pellet production: Norway spruce (Picea abies), representing the class of softwoods, European beech (Fagus sylvatica), a common hardwood and wheat straw, (Triticum aestivum), as a representative for grass type biomass. Norway spruce and beech were harvested in southern Sweden (Skåne/Småland) during the year 2007. Wood stems were collected from the forest in late autumn, after the growth season and debarked. Wheat straw was collected in the year 2007 on the island of Sjælland (Denmark), after the harvesting season and dried on the field. All materials were comminuted into particles $<5 \mathrm{~mm}$ using a hammer mill (Model 55, Jensen and Sommer Aps, Denmark). Prior utilization the materials were kept in air tight plastic containers and had a moisture content of about $8 \%$ (exact values were: beech $7.9 \%$, spruce 8.2 and straw $8 \%$, respectively). Analytical sieves $200 \mathrm{~mm}$ in diameter and a mesh size of $0.5,1,2.8$ and $5 \mathrm{~mm}$. (Analytical sieves, Retsch GmbH, Germany) and a sieve shaker (AS 200, Retsch GmbH, Germany), were used to separate the raw materials in different particle size fractions.

\subsection{Pellet production and pressure determination}

The biomass pellets in this work were produced using single pellet press (SPP) units (designed and constructed at the workshop of the biomass gasification group at Risø-DTU, Roskilde, Denmark) that allow simulation of the pelletizing process in a press channel of a pellet mill by subsequent compression of biomass layers into a pellet. This technology has been used in various pelletizing studies before $[15,18-20]$ and therefore proven its practicability.

For the present study, two SPP units with 8 and $16 \mathrm{~mm}$ channel diameter were used. The units consisted of cylindrical dies (140 mm long) made of hardened steel, lagged with heating elements and thermal insulation. The die wall temperature was controllable between 20 and $180{ }^{\circ} \mathrm{C}$, using a thermocouple, installed in the die wall and connected to a control unit. The end of the die could be 
closed using a backstop. Pressure was applied using metal pistons $7.8 \mathrm{~mm}$ and $15.8 \mathrm{~mm}$ in diameter, for 8 and $16 \mathrm{~m}$ channel diameter. The force was measured using a load cell.

To simulate the pelletizing process within a pellet mill, the pellet has to be built up in sequential layers. Initial experiments to obtain a uniform pellet density, resulting in a linear correlation between the pellet weight and length, have been made, as suggested by Holm et al. [14]. Biomass was loaded in sequential steps, not exceeding $1 \mathrm{~g}$ per layer for the $16 \mathrm{~mm}$ SPP-unit and $0.25 \mathrm{~g}$ per layer for the 8 $\mathrm{mm}$ SPP-unit. The biomass samples were compressed with a maximum pressure of $200 \mathrm{MPa}$ at a rate of $5 \mathrm{~mm} / \mathrm{min}$ using a compression tester (TT-CC, Instron, USA), equipped with a $50 \mathrm{kN}$ load cell (C2S, Nordisk Transducer Teknik, Denmark) and an electronic data collection system. The pressure was released after 5 seconds, the piston removed and a new amount of sample was loaded and compressed until the pellet had the desired dimensions. It has to be noted, that during the production process the material was in the press channel for at least 5 minutes, so that a homogeneous temperature of the pellet could be assumed. After the pellet was pressed, the backstop of the unit was removed and $P_{\mathrm{x}}$ was determined by measuring the maximum pressure, required to press the pellet out of the die at a rate of $5 \mathrm{~mm} / \mathrm{min}$ using a compression tester (TT-CC, Instron, USA). For data recording, a load cell detecting force was connected to a data acquiring system. The die was rinsed with acetone and wiped clean, using a paper towel, when changing raw materials or the die temperature. To study the effect of different processing conditions, biomass pellets have been produced as described under 2.3:

\subsection{Influence of process parameters on $P_{\mathrm{x}}$}

\section{Compression ratio (c)}

Spruce particles $1-2.8 \mathrm{~mm}$ in size and a moisture content of about $8 \%$ were pressed at $20{ }^{\circ} \mathrm{C}$ at 200 MPa using an $8 \mathrm{~mm}$ SPP-unit, with $c$ ranging from 0.1 to 7 . The force required to press the pellet out of the die was determined and pellet length measured directly after pressing using calipers. The obtained experimental data was used for fitting a pellet model (as described in 2.4).

\section{Temperature}

Beech, spruce and straw particles 1-3 $\mathrm{mm}$ in size and a moisture content of about $8 \%$ were used to press pellets in a $16 \mathrm{~mm}$ SPP-unit with $c=2.5$, at temperatures between 20 to $180{ }^{\circ} \mathrm{C}$, at intervals of $20{ }^{\circ} \mathrm{C}$. The force required to press the pellet out of the die was determined, and a minimum of three pellets were produced under the same conditions for calculation of the average and standard deviation. 


\section{Moisture content}

Beech, spruce and straw particles 1-2.8 mm in size were adjusted to moisture contents of $0,5,10$, 15,20 and $25 \%$, by adding an appropriate amount of water using a spray bottle, or by drying of the material in an oven at $105{ }^{\circ} \mathrm{C}$. The material was stored and equilibrated in airtight containers for two weeks before utilization and the final moisture content was verified. Moisture content was analyzed by drying of 1-2 g sample material in an oven at $105{ }^{\circ} \mathrm{C}$ for at least 8 hours and subsequent calculation of the weight loss. Pellets were pressed in a $16 \mathrm{~mm}$ SPP-unit with $c=2.5$ at $20{ }^{\circ} \mathrm{C}$ (to avoid water evaporation during the pelletizing process).

\section{Particle size}

To determine the effect of particle size on $P_{\mathrm{x}}$, beech and spruce with a moisture content of about 8 $\%$ were fractionated into three different fractions: (I) $<0.5 \mathrm{~mm}$, (II) $0.5-1 \mathrm{~mm}$ and (III) $1-2.8 \mathrm{~mm}$ particle size. Pellets were pressed using an $8 \mathrm{~mm} \mathrm{SPP}$-unit with $c=1$ at $20^{\circ} \mathrm{C}$.

\section{Attenuated total reflectance infrared spectroscopy (ATR-FTIR)}

ATR-IR spectra of the pellet surface were recorded, using a Fourier transform infrared spectrometer (Nicolet 6700 FT-IR, Thermo Electron Corporation, USA), equipped with a temperature adjustable ATR accessory (Smart Golden Gate diamond ATR accessory, Thermo Electron Corporation, USA), equilibrated at $30{ }^{\circ} \mathrm{C}$. At least five measurements were performed on each sample. To ensure good contact with the diamond surface, the samples were pressed against it, using a metal rod in a set-up that results in the same mechanical pressure on through the sample. All spectra were obtained with 200 scans for the background (air) and 100 scans for the sample with a resolution of $4 \mathrm{~cm}^{-1}$.

\subsection{Verification of pellet model}

The obtained values for $P_{\mathrm{x}}$ were used to verify the pellet model published earlier [13]. The model fits were carried out as least square fits of the model given in Equation 1 to the press data $P_{\mathrm{x}}$, using modeling software (Matlab R2008b, The Math Works Inc., USA). Due to mutual correlations between the three parameters, the friction coefficient $\mu$ was taken as a constant $(\mu=0.5)$ while the pre-stressing pressure $P_{\mathrm{N} 0}$ and the Poisson ratio $v_{\mathrm{LR}}$ were left free to vary, as suggested by Holm et al. [14].

\subsection{Influence of $P_{\mathrm{x}}$ on pellet density}

Beech and spruce particles 1-2.8 mm in size and a moisture content of about $8 \%$ were used to press pellets at different pressures in an $8 \mathrm{~mm}$ SPP-unit at $20^{\circ} \mathrm{C}$. The applied pelletizing pressure was 50 , 
$100,150,200,250,300,400,600 \mathrm{MPa}$. The unit density of the pellets was calculated by determination of the pellets weight and dimensions for at least five samples at each pressure.

\section{Results and Discussions}

The exponential dependency of $P_{\mathrm{x}}$ on $c$ is shown in Figure 1. The model fit to the experimental data was made to show the exponential increase in the pelletizing pressure as a function of the compression ratio, as suggested in the published theory $[13,14]$. Due to mutual correlations between the three parameters, the friction coefficient was fixed to $\mu=0.5$ obtain a stable fit. The value of the friction coefficient was chosen as a typical value for dry wood on a hard smooth surface, as described in Holm et al. [14]. Keeping the value of the friction coefficient constant, the other parameters were left free to vary. The resulting values of $\mathrm{PN}_{0}$ and $v$ are found to be in the typical range of published values [14].

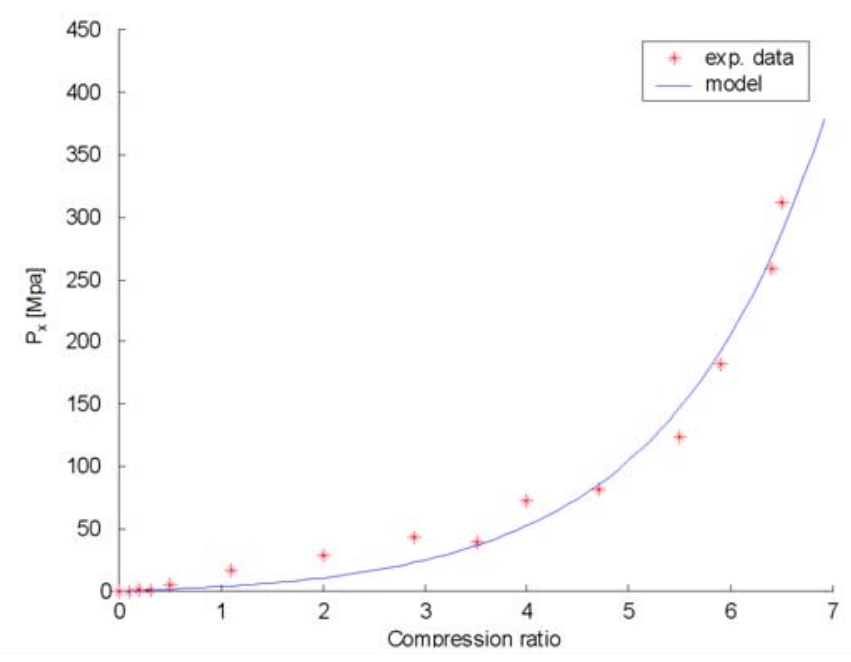

Figure 1. The dependency of $P_{\mathrm{x}}$ on $c$, when pelletizing spruce at $20^{\circ} \mathrm{C}$ and $200 \mathrm{MPa}$ using an $8 \mathrm{~mm}$ SPP-unit. Experimental data $(\mathrm{X})$ and model fit (solid line) with $\mu=0.5, v_{L R}=0.33 \pm 0.03$ and $P N_{0}=13.50 \pm 3.99 \mathrm{MPa}$.

The effect of temperature on $P_{\mathrm{x}}$ in the press channel is shown in Figure 2 for beech, spruce and straw pellets in a temperature range between 20 and $180{ }^{\circ} \mathrm{C}$. 


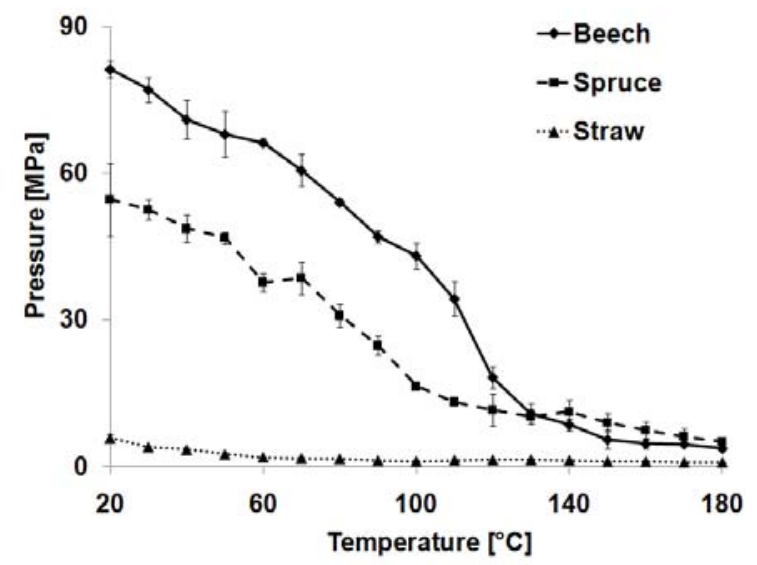

Figure 2. $P_{\mathrm{x}}$ of beech, spruce and straw within a temperature range of $20-180{ }^{\circ} \mathrm{C}$. Measurements were made in a $16 \mathrm{~mm}$ die at a compression ratio of $c=2.5$ and a moisture content of $8 \%$.

$P_{\mathrm{x}}$ decreases with increasing die temperature for all used raw materials. The initial $P_{\mathrm{x}}$ for beech is greater than for spruce, which in accordance with data obtained by Nielsen et al. [15]. They report a decrease of friction with increasing temperature, and the decrease being greater for hardwood beech then for softwood pine. A recent study [19] suggests that wood extractives, a wide range of chemical compounds such as resin compounds, fatty acids, waxes and sterols, might act as lubricants in the press channel, and therefore reduce the friction in the press channel. Softwoods are considered to contain greater amounts of extractives than hardwoods, and this could explain why the pelletizing pressure for spruce is less than for beech, due to the differences in extractives content. A recent work by Stelte et al. [20] using the same raw materials, indicated an extractive content of $1.8 \%$ for spruce and $0.6 \%$ for beech. Furthermore, high extractives content might reduce the temperature dependency of the pelletizing pressure. Both wood materials show a sudden change in slope at $100{ }^{\circ} \mathrm{C}$ for beech and about $70{ }^{\circ} \mathrm{C}$ for spruce. This can be an indication for thermal softening resulting in greater plasticity and flow ability and/or the leeching of extractives to the surface. It is therefore possible that pelletization of softened wood polymers (i.e. hemicelluloses and lignin) resulted in significantly lower pelletizing pressures. The transition temperature at which thermoplastic polymers pass from a glassy to a plastic state is usually referred to as softening point. The temperature at the softening point is the glass transition temperature $\left(T_{g}\right)$ and has been determined for both hemicelluloses and lignin [21-29].

Chow [21] and Goring [22] have shown that lignin and hemicelluloses $\mathrm{T}_{\mathrm{g}}$ range between $77-128^{\circ} \mathrm{C}$ for lignin and $54-142{ }^{\circ} \mathrm{C}$ for hemicelluloses, depending on the woods moisture content. Many 
different studies have been made since, and generally, it can be concluded that the $T_{g}$ of lignin varies considerably depending on the type of wood and the moisture content, and ranges anywhere between 50 and above $100{ }^{\circ} \mathrm{C}$ [25-29]. In case of lignin, it has been shown that its $T_{g}$ varies substantially, depending on its origin [23]. Hardwood lignins have a lower content of free phenolic hydroxyl groups and a substantially higher content of methoxyl groups [24]. This chemical difference results in a significantly lower $T_{g}$ of hardwood lignin than softwood lignins [23]. If lignin passing its softening point is responsible for the sudden drop in $P_{\mathrm{c}}$, then beech, which has a lower $T_{g}$ (hardwood), should show a sharp drop at a temperature lower than spruce, which has a higher $T_{g}$ (softwood). However, from Figure 2, the drop in $P_{\mathrm{x}}$ is at a substantially lower temperature for spruce $\left(\sim 70{ }^{\circ} \mathrm{C}\right)$ than for beech $\left(\sim 100^{\circ} \mathrm{C}\right)$. Thus, lignin softening being responsible to the sharp drop in $P_{\mathrm{x}}$ can be ruled out.

Spruce is known to contain tall oil which is a composition of rosins, unsaponifiable sterols, resin acids, fatty acids, fatty alcohols, some sterols, and other alkyl hydrocarbon derivates [30]. As temperature increases, there is a tendency for extractives to migrate to the surface. The migration of low molecular weight molecules is a common problem in the manufacturing process of traditional wood based formaldehyde boards, where heat treatment can result in a small layer of hydrophobic extractives on the fiber surface, which drastically limit adhesion mechanisms and reduces bonding [31-33]. Spruce has a larger amount of extractives present then beech, and therefore the migration to the surface is most likely responsible for the drop in $P_{\mathrm{x}}$ at about $70{ }^{\circ} \mathrm{C}$. FTIR-ATR spectra also show evidence of wax/oils migrating to the surface at higher temperatures which will be discussed later.

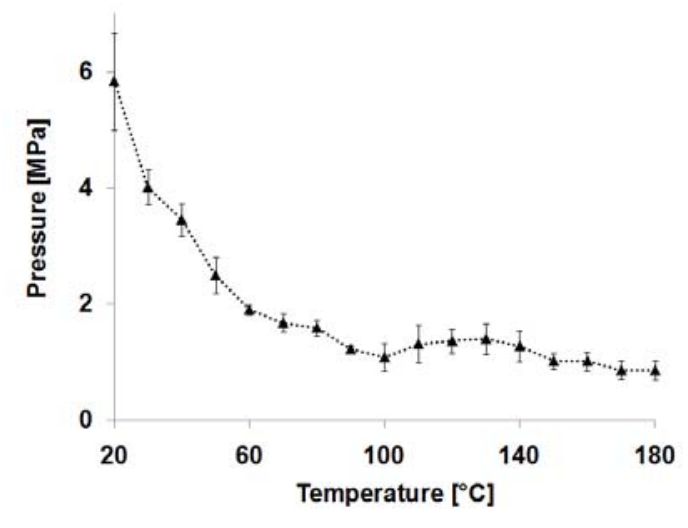

Figure 3. $P_{\mathrm{x}}$ of straw within a temperature range of $20-180{ }^{\circ} \mathrm{C}$. Measurements were made in a $16 \mathrm{~mm}$ die at a compression ratio of $c=2.5$. 
Figure 3 shows the same correlation for straw, but at a larger scale, indicating that straw also exhibits a drop in pressure. The pressure drop is closer to ambient conditions in comparison with either beech or spruce, which is most likely an effect of the different chemical composition of the biomass surface. $P_{\mathrm{x}}$ starts to decrease at temperatures above $20{ }^{\circ} \mathrm{C}$ up to $140{ }^{\circ} \mathrm{C}$. Major chemical difference between grasses and wood is the waxy cuticula on the grass surface that could act as a lubricant, resulting in significantly lower friction, compared to woody biomass, and might also contribute to different thermo mechanical behavior. As the temperature increases the waxes soften and enhance its lubricating effect.

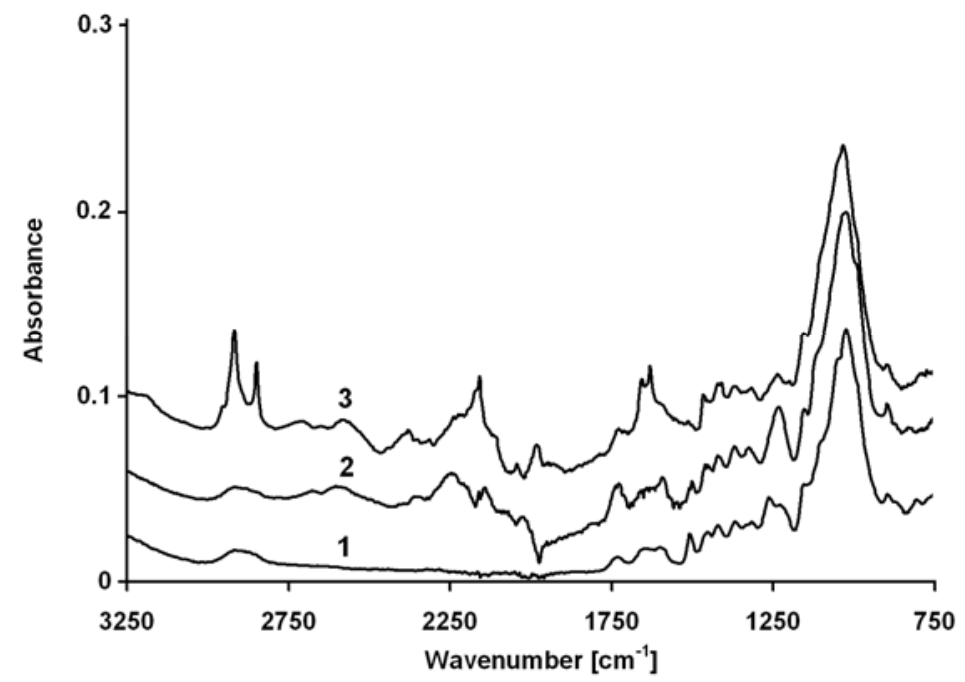

Figure 4. ATR-IR Spectra of the pellet surface of beech (1), spruce (2) and straw (3) pellets made at $20{ }^{\circ} \mathrm{C}$ 


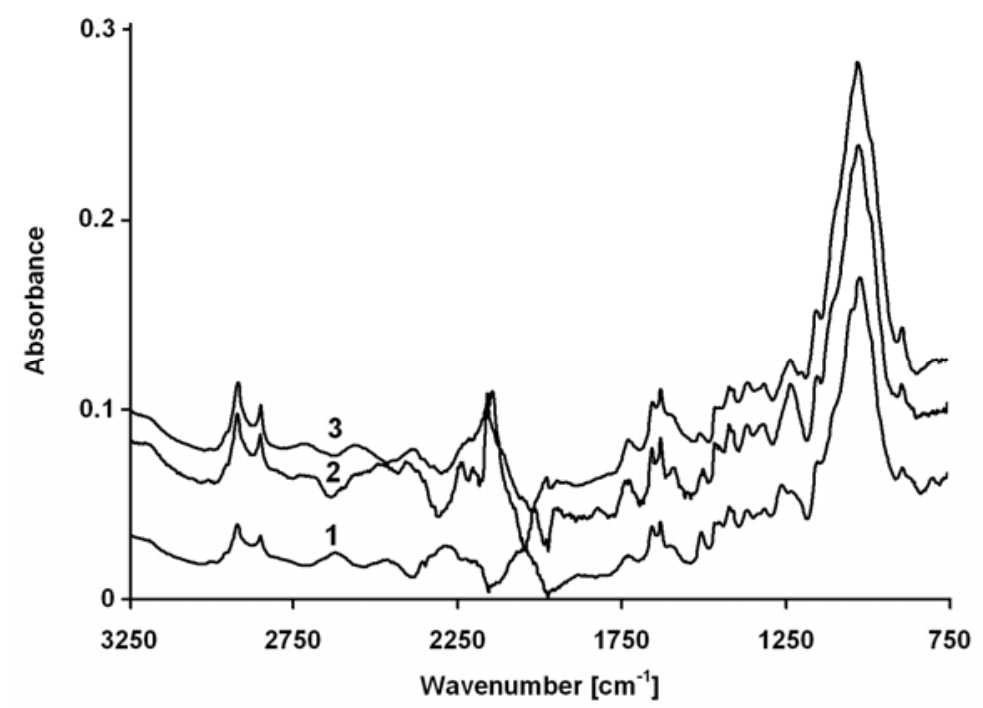

Figure 5. ATR-IR Spectra of the pellet surface of beech (1), spruce (2) and straw (3) pellets made at $100{ }^{\circ} \mathrm{C}$.

Infrared spectra taken from the pellets surface in Figures 4 and 5 indicate a difference between pellets pressed at 20 and $100{ }^{\circ} \mathrm{C}$. The bands at 2800 and $2900 \mathrm{~cm}^{-1}$, which are related to $\mathrm{C}-\mathrm{H}$ stretches, have earlier been linked to hydrophobic extractives such as waxes and oils [34]. There are only minor differences in the spectra of straw pellets produced at 20 and $100{ }^{\circ} \mathrm{C}$, which can be explained by the fact that straw naturally is coated by a cuticula, rich in low molecular weight waxes. There is no sign of the $\mathrm{C}-\mathrm{H}$ stretch for either wood species at $20^{\circ} \mathrm{C}$. In case of the wood pellets, both species show a C-H stretching bands for pellets pressed at $100{ }^{\circ} \mathrm{C}$, and this is due to migration of extractives to the pellet surface during pellet production. Low molecular weight hydrocarbons, such as oils and waxes, are known to reduce the friction, and their increased content on the pellets surface might be linked to the reduced pelletizing pressure shown in Figure 2 and 3. The spruce $\mathrm{C}-\mathrm{H}$ stretching bands at $100^{\circ} \mathrm{C}$ seem to be an order of magnitude greater than those of beech. After about $130{ }^{\circ} \mathrm{C}, P_{\mathrm{x}}$ seems to be similar and this could be due to softening of the lignin, so that the particles are more flexible. 


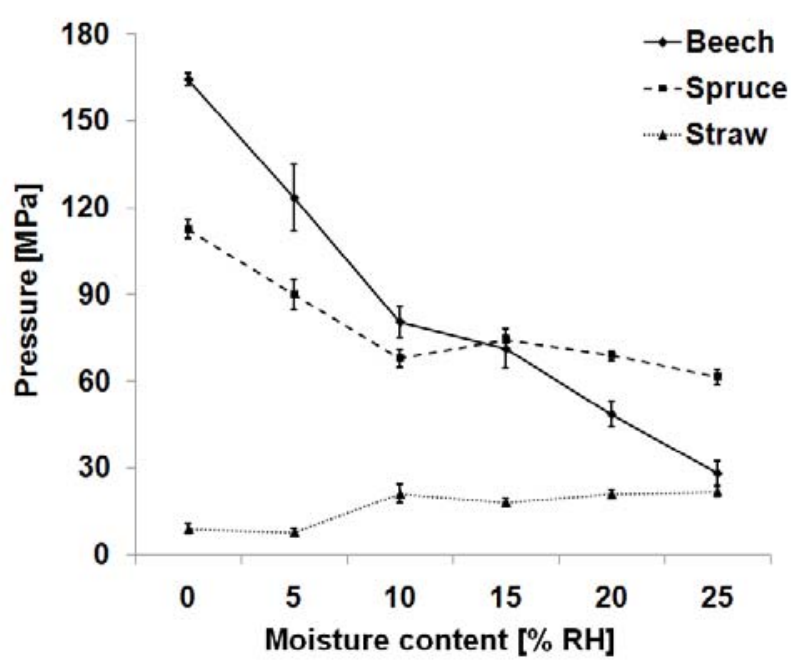

Figure 6. Effect of moisture content on $P_{\mathrm{x}}$ when pelletizing beech, spruce, and straw in a $16 \mathrm{~mm}$ die at $20{ }^{\circ} \mathrm{C}$ and $c=2.5$.

Figure 6 shows the dependency of $P_{x}$ on the moisture content of the substrate. It can be seen that for beech and spruce an increasing moisture content of the raw materials, results in a drop of $P_{\mathrm{x}}$, which is more pronounced for beech than for spruce. The presence of moisture is known to plasticize the amorphous regions in wood, and it is possible that this increases the flowabilty of hemicelluloses and other low $T_{g}$ extractives, thus reducing $P_{\mathrm{x}}$ for beech and spruce. Chow [21], Goring [22], Salmen and Olson [35] and Kelley, et al. [27] have shown strong decrease in $T_{g}$ of the amorphous components of spruce with an increase in moisture content. Further work needs to be done to see why spruce and beech behave differently. Wood as a material is brittle, when dry and shows low flexibility, when most of its water has been removed, and this could explain the high $P_{\mathrm{x}}$ due to high friction, when pelletizing dried beech and spruce. If water is present, inter and intra molecular hydrogen bonds between the wood polymers are substituted with hydrogen bonds to water molecules. Water molecules act as a plasticizer which increases the flexibility and softness of the material, resulting in lower friction within the press channel. It is also possible that the presence of moisture enhances the migration of the waxes or oils to the surface at lower temperatures, but this has yet to be confirmed. 


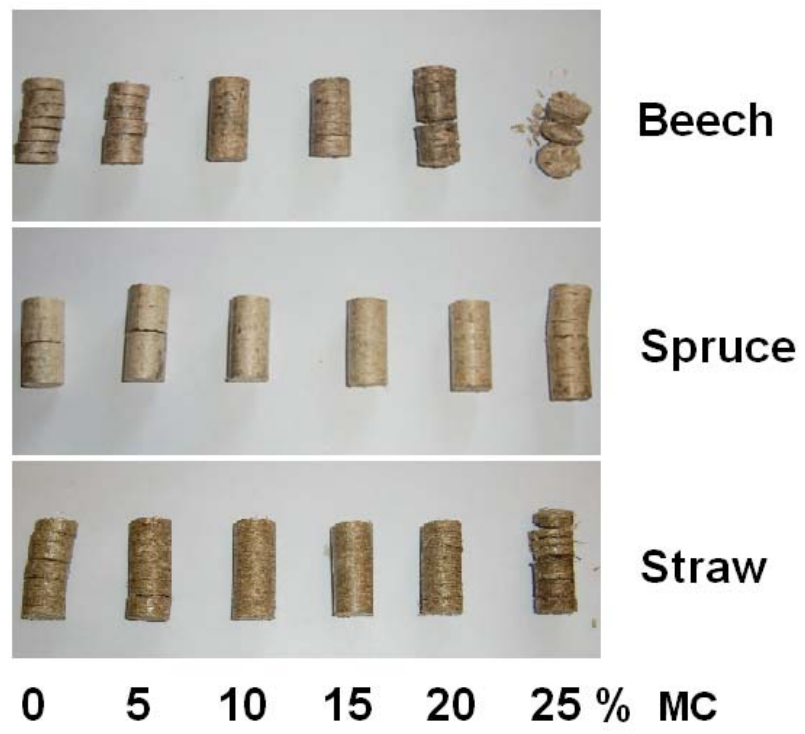

Figure 7. Effect of moisture content on pellet stability of beech, spruce and straw pellet pressed in a $16 \mathrm{~mm}$ SPP unit at $20^{\circ} \mathrm{C}$.

The pellet stability or integrity was best in the range between $5-15 \%$, as shown in Figure 7, and no stable pellets were formed at moisture contents above $20 \%$. It is possible that many hydrogen bonds between the wood polymers are substituted with bonds to water molecules thereby reducing the strength of the pellet. However, a minimum amount of moisture is needed to improve inter-particular adhesion/attraction. Figure 7 clearly shows that for completely dry biomass the integrity of the pellets is very poor.

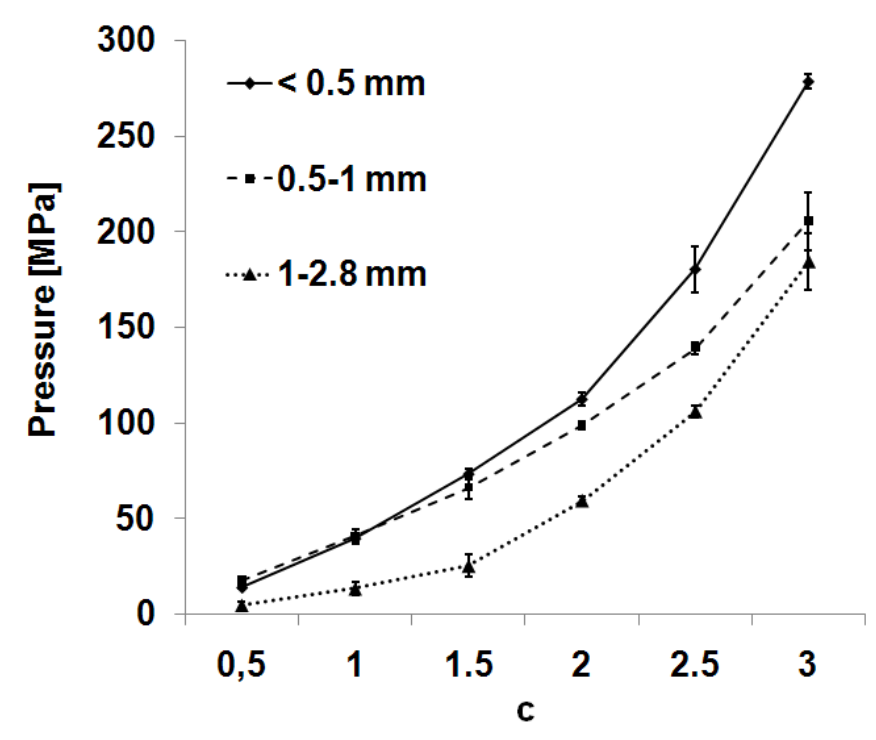


Figure 8. Effect of particle size on $P_{\mathrm{x}}$ when pelletizing beech at various $c$ in an $8 \mathrm{~mm}$ die at $20^{\circ} \mathrm{C}$.

The effect of particle size on $P_{\mathrm{x}}$ at different $c$ is shown in Figure 8 and it can be seen that there is a clear correlation between particle size and $P_{\mathrm{x}}$, indicating that friction increases with decreasing particle size. Lower particle size is likely to result in higher surface area of contact between the pellet and the walls resulting in greater friction.

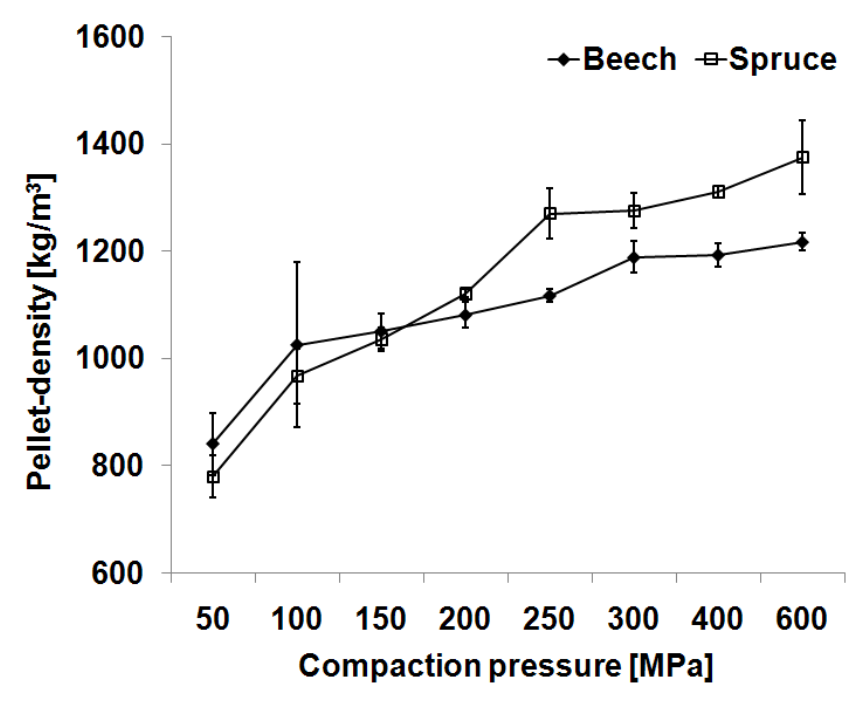

Figure 9. Dependency of pellet density on pressure applied during the pelletizing process.

Measurements made in an $8 \mathrm{~mm}$ die at $20{ }^{\circ} \mathrm{C}$ and with $c=1$.

The density of a wood pellet increases with increasing pressure applied onto the biomass as shown in Figure 9. The absolute upper limit for the possible density of a pellet made of plant material is likely the density of the plant cell wall which has been determined to be in the range between 1420 $1500 \mathrm{~kg} / \mathrm{m}^{3}[36,37]$. The closer the pellet density approximates the upper limit the less it will increase with increasing pressure. It seems therefore reasonable that there is a limit how much the biomass can be compressed, and that a further increase of pressure does not result in higher pellet density. It appears that the greatest decrease in volume is at pressures below $50 \mathrm{MPa}$, while in the range between 200-600 MPa only small changes in pellet density were observed. 


\section{Conclusions}

The present study has evaluated the impact of pellet length, die temperature, biomass moisture content and particle size on the pelletizing pressure during fuel pellet production from biomass. It has been shown that the pelletizing pressure increases exponentially with the pellet length. A mathematical model, predicting the increasing pelletizing pressure was in good accordance with experimental data. The pelletizing pressure was shown to be dependent on biomass species, temperature, moisture content and particle size. An increasing temperature of the die during pelletization decreased the pelletizing pressure, and infrared spectra of the pellet surface indicated hydrophobic extractives for pellets produced at higher temperatures that might have acted as a lubricant reducing the friction between biomass and steel surface. The influence of the biomass moisture content was ambiguous and depending on the biomass type. For woody samples, the pelletizing pressure dropped with increasing moisture content while it increased for wheat straw. The effect of particle size on the pelletizing pressure was more defined, showing that the pelletizing pressure increases with a decreasing particle size. An increasing pelletizing pressure is resulting in an increasing pellet density and it was shown that pressures above $250 \mathrm{MPa}$ resulted only in minor increase in pellet density.

\section{Acknowledgements}

The present study was conducted under the framework of the Danish Energy Agency's EFP project: "Advanced understanding of biomass pelletization" ENS-33033-0227. The authors wish to thank Vattenfall A/S, DONG Energy A/S and the Danish Energy Agency for financial support.

\section{References}

[1] Rosillo-Calle F, Hemstock S, de Groot, P., Woods J. The Biomass Assessment Handbook. London: Earthscan; 2007. 
[2] Smeets EMW, Faaij APC, Lewandowski IM, Turkenburg WC. A bottom-up assessment and review of global bio-energy potentials to 2050. Prog Energy Combust Sci 2007;33:56-106.

[3] Adapa PK, Tabil LG, Schoenau GJ, Crerar B, Sokhansanj S. Compression characteristics of fractionated alfalfa grinds. Powder Handling and Processing 2002;14:252-9.

[4] Larsson SH, Thyrel M, Geladi P, Lestander TA. High quality biofuel pellet production from pre-compacted low density raw materials. Bioresour Technol 2008;99:7176-82.

[5] Simpson W, TenWolde A. Physical properties and moisture relations of wood. In: Wood handbook - Wood as an engineering material. Madison: United states department of agriculture Forest Service - Forest products laboratory; 1999.

[6] Robbins WC. Density of wood chips. J Forest 1982;80:567.

[7] Presslinge aus naturbelassenem Holz - Anforderungen und Prüfung, DIN 51731: 1996-10. 1996.

[8] Sokhansanj S, Turhollow AF. Biomass densification - Cubing operations and costs for corn stover. Appl Eng Agri 2004;20:495-9.

[9] Junginger M, Sikkema R, Faaij A. Analysis of the global pellet market. Utrecht: Copernicus Institute, Utrecht University; 2009.

[10] Verma VK, Bram S, Delattin F, Laha P, Vandendael O, Hubin A, De Ruyck J. Agro-pellets for domestic heating boilers: Standard laboratory and real life performance. Appl Energy 2011, doi:10.1016/j.apenergy.2010.12.079. Article in press.

[11] Sultana A, Kumar A, Harfield D. Development of agri-pellet production cost and optimum size. Biores Technol 2010;101:5609-5621.

[12] Bhattacharya SC, Sett S, Shrestha RM. State of the art for biomass densification. Energy Sources 1989;11:161-82.

[13] Holm JK, Henriksen UB, Hustad JE, Sorensen LH. Toward an understanding of controlling parameters in softwood and hardwood pellets production. Energy Fuels 2006;20:2686-94.

[14] Holm JK, Henriksen UB, Wand K, Hustad JE, Posselt D. Experimental verification of novel pellet model using a single pelleter unit. Energy Fuels 2007;21:2446-9. 
[15] Nielsen NPK, Holm JK, Felby C. Effect of fiber orientation on compression and frictional properties of sawdust particles in fuel pellet production. Energy Fuels 2009;23:3211-6.

[16] Nielsen NPK, Nørgaard L, Strobel BW, Felby C. Effect of storage on extractives from particle surfaces of softwood and hardwood raw materials for wood pellets. Eur J Wood Prod 2009;67:19-26.

[17] Nielsen NPK, Gardner DJ, Poulsen T, Felby C. Importance of temperature, moisture content, and species for the conversion process of wood into fuel pellets. Wood Fiber Sci 2009;41:414-25.

[18] Nielsen NPK, Gardner DJ, Felby C. Effect of extractives and storage on the pelletizing process of sawdust. Fuel 2010;89:94-8.

[19] Finell M, Arshadi M, Gref R, Scherzer T, Knolle W, Lestander T. Laboratory-scale production of biofuel pellets from electron beam treated Scots pine (Pinus silvestris L.) sawdust. Radiat Phys Chem 2009;78:281-7.

[20] Stelte W, Holm JK, Sanadi AR, Barsberg S, Ahrenfeldt J, Henriksen UB. A study of bonding and failure mechanisms in fuel pellets made from different biomass resources. Biomass Bioenergy 2011;35:910-918.

[21] Chow SZ, Pickles KJ. Thermal softening and degradation of wood and bark. Wood Fiber 1971;3:166-178.

[22] Goring DAI. Thermal softening of lignin, hemicellulose and cellulose. Pulp Paper Mag Canada 1971;64:512-27.

[23] Olsson AM, Salmen L. Viscoelasticity of insitu lignin as affected by structure - softwood vs hardwood. In: Glasser, W. editor. Viscoelasticity of Biomaterials. ACS Symposium Series 489. Washington: American Chemical Society 1992.p.133-43.

[24] Sjöström E. Wood Chemistry: Fundamentals and Applications. London: Academic Press; 1983.

[25] Salmen L. Viscoelastic properties of insitu lignin under water-saturated conditions. J Mater Sci 1984;19:3090-6.

[26] Irvine GM. The glass transitions of lignin and hemicellulose and their measurement by differential thermal-analysis. Tappi J 1984;67:118-21.

[27] Kelley SS, Rials TG, Glasser WG. Relaxation behavior of the amorphous components of wood. J Mat Sci 1987;22:617-24. 
[28] Hatakeyama H, Hatakeyama T. Thermal properties of isolated and in situ lignin. In: Heitner C, Dimmel D, Schmidt J, editors. Lignin and Lignans: Advances in Chemistry. New York: CRC Press; 2010, p. 301.

[29] Stelte W, Clemon C, Holm JK, Ahrenfeldt J, Henriksen UB, Sanadi A. Thermal transitions of the amorphous polymers in wheat straw. Ind Crop Prod 2011 doi10.1016/j.indcrop.2011.03.014. Article in press.

[30] Biermann CJ. Essentials of Pulp and Papermaking. San Diego: Academic Press Inc.; 1993,p.107.

[31] Bikerman JJ. The science of adhesive joints. New York: Academic Press; 1961.

[32] Bikerman JJ. Causes of poor adhesion - weak boundary layers. Ind Eng Chem 1967;59:40-4.

[33] Stehr M, Johansson I. Weak boundary layers on wood surfaces. J Adhes Sci Technol 2000;14:1211-24.

[34] Merk S, Blume A, Riederer M. Phase behaviour and crystallinity of plant cuticular waxes studied by Fourier transform infrared spectroscopy. Planta 1998;204:44-53.

[35] Salmen L, Olsson AM. Interaction between hemicelluloses, lignin and cellulose: Structureproperty relationships. J Pulp Paper Sci 1998;24:99-103.

[36] Hill CAS, Ormondroyd GA. Dimensional changes in Corsican pine (Pinus nigra Arnold) modified with acetic anhydride measured using a helium pycnometer. Holzforschung 2004;58:544-7.

[37] Kellogg RM, Wangaard FF. Variation in cell-wall density of wood. Wood Fiber Sci 1969;1:180-204. 